\title{
Prophylaxis of thromboembolic complications after the Fontan operation (total cavopulmonary anastomosis)
}

\author{
Renate Kaulitz, MD \\ Gerhard Ziemer, MD \\ Ralf Rauch, MD \\ Monika Girisch, MD \\ Harald Bertram, MD \\ Armin Wessel, MD \\ Michael Hofbeck, MD
}

See related editorial on page 491.
From the Department of Pediatric Cardiology and Pediatric Intensive Care Medicine, ${ }^{a}$ Tuebingen University Hospital and Hannover Medical School, and the Department of Thoracic, Cardiac and Vascular Surgery, ${ }^{\mathrm{b}}$ Tuebingen University Hospital, Tuebingen, Germany.

Received Feb 26, 2004; revisions received Aug 11, 2004; accepted for publication Aug 20, 2004.

Address for reprints: Renate Kaulitz, MD, Department of Pediatric Cardiology and Pediatric Intensive Care Medicine, Tuebingen University Hospital, Hoppe-Seyler Str 3, D-72076, Tuebingen, Germany (E-mail: renate.kaulitz@med.uni-tuebingen.de).

J Thorac Cardiovasc Surg 2005;129:569-75 0022-5223/\$30.00

Copyright (C) 2005 by The American Association for Thoracic Surgery

doi:10.1016/j.jtcvs.2004.08.045
Objectives: Thrombotic events have been reported as a major cause of morbidity after the Fontan procedure. There is no consensus concerning the postoperative mode and duration of anticoagulation prophylaxis. In a retrospective study, we evaluated the results of a prophylactic regimen on the basis of the surgical technique, potentially predisposing risk factors, and specific sequelae.

Methods: We evaluated 142 surviving patients after total cavopulmonary anastomosis (mean follow-up was $91.1 \pm 43.9$ months). Prophylactic antithrombotic treatment was initiated in 86 patients with partial prosthetic venous pathway with acetylsalicylic acid; 45 patients with complete autologous tissue venous pathway or partial prosthetic venous pathway received no anticoagulation, and 11 patients received warfarin sodium (Coumadin). During long-term follow-up, 22 patients (12 after acetylsalicylic acid medication) crossed over to warfarin.

Results: Thrombotic events occurred in 10 patients (7\%), with systemic venous thrombus formation in $8(5.6 \%)$, stroke in $2(1.4 \%)$, and a peak incidence during the first postoperative year. Eight of 10 patients were receiving heparin therapy mainly for prolonged postoperative immobilization. During follow-up, none of the 74 patients receiving acetylsalicylic acid and 1 of 40 patients without medication presented with thrombus formation. Under warfarin medication, 1 of 28 patients had an asymptomatic thrombus. Expected freedom from a thromboembolic event was $92 \%$ at 5 years and $79 \%$ at 10 years. There was no association with coagulation factor abnormalities. Protein-losing enteropathy was present in 4 of 10 patients.

Conclusion: A prophylactic anticoagulation strategy that considers the surgical technique and potential predisposing circumstances proved effective in the prevention of late thrombotic complications after total cavopulmonary anastomosis. There is no need for routine anticoagulation during long-term follow-up after Fontan-type surgery in pediatric patients.

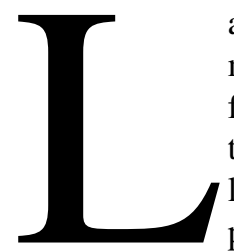

ate morbidity and long-term prognosis after the Fontan operation are mainly determined by atrial dysrhythmia, systemic ventricular dysfunction, protein-losing enteropathy, hepatic dysfunction, and thromboembolic complications. ${ }^{1-3}$ Few data are available that analyze the time course of thromboembolism and that demonstrate a persistent implied risk throughout the time of follow-up. ${ }^{4}$ Systemic venous thromboembolic complications have been described in $3 \%$ to $20 \%$. $^{4-6}$ The incidence of arterial thromboembolic events ranged from 3\% to $19 \%$ in one of the earliest publications. ${ }^{7}$ The large variance in the incidence of thrombus formation 
TABLE 1. Patient data $(n=142)$

\begin{tabular}{lc}
\hline & $\mathbf{n}(\%)$ \\
\hline Diagnosis & $30(21.1)$ \\
Tricuspid atresia & $30(21.1)$ \\
Double-inlet ventricle & $82(57.7)$ \\
Complex univentricular heart & $14(9.8)$ \\
Heterotaxy syndrome & $121(85.2)$ \\
Fontan procedure & \\
Total cavopulmonary anastomosis & \\
$\quad$ (with fenestration $n=38)$ & $21(14.7)$ \\
$\quad$ (with autologous intra-atrial & Mean \pm SD(range) \\
$\quad$ tunnel $n=16)$ & $66.3 \pm 57.9(6-393 \mathrm{mo} 5)$ \\
Extracardiac conduit & $67.8 \pm 52.1(7-393 \mathrm{mo})$ \\
Age at Fontan procedure & $49.5 \pm 39.7(6-151 \mathrm{mo})$ \\
Total & Mean \pm SD (range) \\
Total cavopulmonary anastomosis & $91.1 \pm 43.9(12-177 \mathrm{mo})$ \\
Extracardiac conduit & $91.8 \pm 34.1(18-129 \mathrm{mo})$ \\
Follow-up & $48.3 \pm 21.7(12-81 \mathrm{mo})$ \\
Total & \\
Total cavopulmonary anastomosis & \\
Extracardiac conduit & \\
\hline
\end{tabular}

might reflect the results of different modifications of the Fontan procedure, the various durations of postoperative follow-up, and the diagnostic method used to identify intracardiac thrombi in the majority of asymptomatic patients. ${ }^{5,6,8,9}$ Liver dysfunction or protein-losing enteropathy may result in changes of synthesis of procoagulant and anticoagulant factors, influencing the balance of the coagulation and fibrinolytic system. ${ }^{3,10-12}$

The optimum type and duration of postoperative anticoagulation therapy is still a matter of discussion because no controlled studies comparing different strategies preventing thromboembolic complications are available yet. Initial anticoagulation with warfarin sodium (Coumadin) has been recommended by some authors for all patients after Fontantype surgery irrespective of the individual situation. ${ }^{5,12,13}$

In this study we analyzed the initial intention to treat and assessed the results of a long-term risk-stratified prophylactic treatment depending on the potential predisposing circumstances in our patients after a total cavopulmonary anastomosis.

\section{Patients and Methods}

This is a retrospective study on 142 surviving patients who underwent a total cavopulmonary anastomosis between 1988 and 2002 performed by 1 surgeon at 2 institutions (Table 1). Ethical committee approval was obtained, and informed consent was given by all patients and their parents.

A total cavopulmonary anastomosis was accomplished by a lateral partial prosthetic tunnel procedure in 121 patients (including 38 patients with tunnel fenestration). In 16 of these patients, the lateral tunnel was created with only autologous tissue. An extracardiac conduit procedure was performed in 21 patients. A patent pulmonary valve was closed at the annulus level during the Glenn or Fontan procedure in all patients except one. The age at operation varied from 6 to 393 months (mean $66.3 \pm 57.9$ months). The early postoperative period was defined as the time before discharge or the first 30 postoperative days. The duration of follow-up was $91.1 \pm 43.9$ months (range 12-177 months) with 46 patients $(32.3 \%)$ followed up for more than 10 years. Data on postoperative cardiac catheterization were available for 97 patients. Yearly outpatient follow-up examinations included transthoracic echocardiography with a Hewlett-Packard (Palo Alto, Calif) ultrasound system (2.5-5 MHz transducer). Transthoracic echocardiography was followed by transesophageal evaluation in patients with a clinical suspicion of thrombus formation, a questionable finding on transthoracic echocardiography, or an increased level of D-dimer as a potential marker of fibrinolysis. Transesophageal echocardiography was also performed routinely before cardiac catheterization. Thrombus formation at the atrial, ventricular, or vascular level was defined as an echogenic mass adherent to cardiac structures and described with regard to localization and size. Laboratory investigations were performed for hereditary thrombophilia and coagulation factor analysis on a cross-sectional basis including screening for prothrombotic state with imbalance of procoagulation and anticoagulation factors and liver dysfunction. Late dysrhythmia was defined as sinuatrial dysfunction or intra-atrial reentry tachycardia (IART) with the need for antiarrhythmic medication. ${ }^{14}$ Protein-losing enteropathy was diagnosed in patients with clinical symptoms related to hypoproteinemia; when indicated, the $a_{1}$-antitrypsin clearance was calculated. $^{15}$

The initial antithrombotic treatment was based on the surgical method and influenced by preoperative parameters and early postoperative functional result. It was modified during long-term follow-up when thromboembolic complications occurred or sequelae such as atrial tachydysrhythmia, symptomatic protein-losing enteropathy, polycythemia, or ventricular dysfunction associated with systemic venous slow blood flow phenomenon on echocardiogram developed. This resulted in 22 cross-overs to warfarin during follow-up.

After the early postoperative period, 85 patients with a partial prosthetic venous pathway (including patients with tunnel fenestration) were treated with acetylsalicylic acid (ASA; 3-5 mg/kg per day). No anticoagulation was administered to 16 patients with autologous tissue venous pathways and 29 patients with partial prosthetic venous pathways and an uncomplicated early postoperative period. Six patients received warfarin as initial treatment because of borderline preoperative hemodynamic parameters or related to surgical technique. Eight patients received heparin for prolonged pleural effusions or immobilization and crossed over to ASA or warfarin during follow-up (Figure 1).

\section{Statistical Analysis}

When appropriate, data were expressed as mean \pm standard deviation. All data were analyzed using SPSS statistical software (SPSS Inc, Chicago, Ill). Numeric data were analyzed with the unpaired $t$ test; categorical data were analyzed with chi-square analysis. 


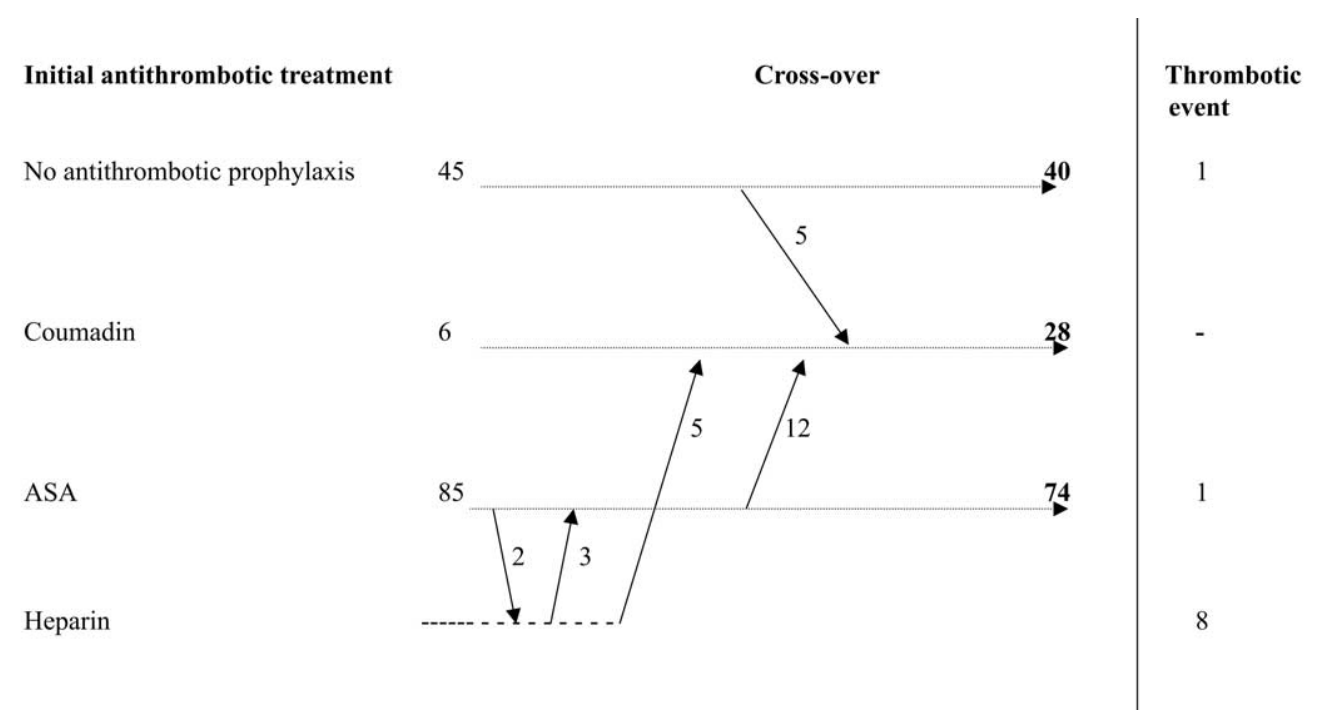

Figure 1. Antithrombotic treatment.

\section{Results}

\section{Incidence of Thrombus Formation and} Thromboembolic Events

A total of 142 survivors were assessed (none of the patients who died during the early or late postoperative period died of a thromboembolic event or thrombus formation). Thrombus formation and thromboembolic events occurred in 10 patients $(7 \%)$. Eight of these patients $(5.6 \%)$ presented with systemic venous thrombus formation, whereas arterial emboli resulted in a stroke in 2 patients (1.4\%) (Table 2). Six of 8 patients with right-sided thrombi were asymptomatic; 2 patients (patients 1 and 5) had symptoms of supraventricular tachycardia and venous congestion, respectively. In 3 additional patients (patients 6, 7, and 9), venous thrombus formation was detected on the routine postoperative echocardiogram during the early postoperative period. Potential predisposing factors were postoperative immobilization or a central venous line. Late asymptomatic systemic venous thrombi were detected in 3 patients (patients 2, 3, and 4); symptomatic protein-losing enteropathy had already developed in 2 patients.

A stroke was the first symptom of a thromboembolic complication in 2 patients (patients 8 and 10). This occurred before discharge in the presence of prolonged postoperative immobilization and protein-losing enteropathy in 1 patient. The second patient was admitted 20 months after the Fontan-type procedure with neurologic signs of a stroke; 6 weeks before, he had been placed on high molecular weight heparin $\left(5000 \mathrm{U} / \mathrm{m}^{2}\right.$ bovine serum albumin subcutaneously) for treatment of recurrent symptomatic protein-losing enteropathy. Altogether, 8 of 10 patients with thromboembolic events received heparin (administered intravenously in 7 patients [maintenance dosage 15-25 $\mathrm{U} \mathrm{kg}^{-1} \cdot \mathrm{h}^{-1}$ ] and subcutaneously in 1 patient) at the time of thrombus formation, mainly for postoperative immobilization (Table 2), and presented with a partial thromboplastin time of 50 to 60 seconds or more (except for patient 6). The Kaplan-Meier estimate for freedom from a thrombotic or thromboembolic event (systemic venous or arterial) is $91.6 \%$ at 5 years and $78.8 \%$ at 10 years (Figure 2).

\section{Risk-Stratified Anticoagulant Prophylaxis During Long-Term Follow-up}

According to initial management, 45 patients (including 16 patients with autologous venous pathway) received no anticoagulation. During long-term follow-up, 5 patients crossed over to warfarin (Figure 1) because of complications or functional sequelae in 3 and a thromboembolic event in 1. One patient crossed over to warfarin because of a patent pulmonary valve with residual pulmonary artery stump, as recommended in recent studies. ${ }^{16,17}$ None of the remaining 40 patients had specific sequelae of the Fontan circulation during long-term follow-up; so far, 38 patients have undergone cardiac catheterization confirming an adequate morphologic and hemodynamic result. A total of 85 patients were initially treated with ASA; 74 patients who remained on long-term ASA medication (Figure 1) crossed over to warfarin because of functional sequelae of the Fontan circulation or a thromboembolic event. None of these patients presented with clinical symptoms of thromboembolic events or suspicious findings on transthoracic echocardiogram; 45 patients had undergone cardiac catheterization combined with transesophageal echocardiography to exclude any tunnel obstruction.

The number of patients who received warfarin increased from 6 to 28 during follow-up. Cross-over to warfarin was 
TABLE 2. Patients with thromboembolic events

\begin{tabular}{|c|c|c|c|}
\hline & Patient 1 & Patient 2 & Patient 3 \\
\hline Anatomy & PA/IVS & DORV, MGA, & DILV, TGA, coarctation \\
\hline Surgery & TCPA & TCPA & TCPA \\
\hline Age at operation & $135 \mathrm{mo}$ & $57 \mathrm{mo}$ & 114 mo \\
\hline \multicolumn{4}{|l|}{ Thrombus formation } \\
\hline Localization & iT & iT & iT \\
\hline Interval to surgery & $12 \mathrm{~d}$ & $108 \mathrm{mo}$ & $3 \mathrm{mo}$ \\
\hline Symptoms & SVT & - & - \\
\hline Prophylaxis of thrombus at diagnosis & Heparin & - & Warfarin \\
\hline Potential predisposing circumstances & Anastomosis stenosis & - & Ventricular dysfunction, PLE \\
\hline Thrombus therapy & Reoperation (anastomosis revision) & Warfarin & $\mathrm{rt}-\mathrm{PA}$ \\
\hline Long-term prophylaxis & $\begin{array}{l}\text { ASA for the first postop year; } \\
\text { beginning warfarin } 12 \text { y postop }\end{array}$ & Warfarin & Warfarin \\
\hline
\end{tabular}

\begin{tabular}{|c|c|c|c|}
\hline & \multicolumn{2}{|c|}{ Patient 4} & Patient 5 \\
\hline Anatomy & \multicolumn{2}{|l|}{ HLHS } & DORV, MGA \\
\hline Surgery & \multicolumn{2}{|l|}{ TCPA } & Fenestrated TCPA \\
\hline Age at operation & \multirow{2}{*}{\multicolumn{2}{|c|}{$27 \mathrm{mo}$}} & $9 \mathrm{mo}$ \\
\hline \multicolumn{2}{|l|}{ Thrombus formation } & & \\
\hline Localization & \multicolumn{2}{|l|}{ iT } & Fenestration \\
\hline Interval to surgery & \multicolumn{2}{|l|}{49 mo } & \\
\hline Symptoms & \multicolumn{2}{|l|}{ - } & $\begin{array}{l}\text { Increased systemic venous } \\
\text { pressure }\end{array}$ \\
\hline Prophylaxis of thrombus at diagnosis & \multicolumn{2}{|l|}{ Heparin } & Heparin \\
\hline Potential predisposing circumstances & \multicolumn{2}{|c|}{$\begin{array}{l}\text { Postop immobilization } \\
\text { (pacemaker revision), PLE }\end{array}$} & $\begin{array}{l}\text { Venous stasis, increased } \\
\text { PAP }\end{array}$ \\
\hline Thrombus therapy & \multirow{2}{*}{\multicolumn{2}{|c|}{$\begin{array}{l}\text { Warfarin } \\
\text { Warfarin }\end{array}$}} & Reoperation (refenestration) \\
\hline \multirow[t]{2}{*}{ Long-term prophylaxis } & & & ASA \\
\hline & Patient 6 & Patient 7 & Patient 8 \\
\hline Anatomy & $\begin{array}{l}\text { Heterotaxy syndrome, } \\
\text { SV, SA, TAPVD, SPS }\end{array}$ & $\begin{array}{l}\text { Heterotaxy syndrome, } \\
\text { CAVSD, TGA, PA, } \\
\text { PAPVD, bilateral SVC }\end{array}$ & TA Ic \\
\hline Surgery & TCPA & Extracardiac CPC & TCPA \\
\hline Age at operation & $132 \mathrm{mo}$ & $52 \mathrm{mo}$ & $68 \mathrm{mo}$ \\
\hline \multicolumn{4}{|l|}{ Thrombus formation } \\
\hline Localization & iT & SVC & Not detected \\
\hline Interval to surgery & $25 \mathrm{~d}$ & $6 \mathrm{~d}$ & $2 \mathrm{mo}$ \\
\hline Symptoms & - & - & \\
\hline \multicolumn{4}{|l|}{ Cerebrovascular accident } \\
\hline Prophylaxis of thrombus at diagnosis & Heparin & Heparin & Heparin \\
\hline Potential predisposing circumstances & $\begin{array}{l}\text { Postop immobilization } \\
\text { (pleural drainage) }\end{array}$ & Central venous line & $\begin{array}{l}\text { Postop immobilization PLE } \\
\text { (cholelithiasis, drainage) }\end{array}$ \\
\hline Thrombus therapy & rt-PA & Heparin & Heparin \\
\hline \multirow[t]{2}{*}{ Long-term prophylaxis } & $\begin{array}{l}\text { ASA, beginning } \\
\text { warfarin } 3 \text { y postop }\end{array}$ & ASA & Warfarin \\
\hline & \multicolumn{2}{|c|}{ Patient 9} & Patient 10 \\
\hline Anatomy & \multicolumn{2}{|c|}{ DORV, TGA, SPS, PS } & TA Ilc \\
\hline Surgery & \multicolumn{2}{|c|}{ TCPA } & Fenestrated TCPA \\
\hline Age at operation & \multirow{2}{*}{\multicolumn{2}{|c|}{7 mo }} & $20 \mathrm{mo}$ \\
\hline \multicolumn{3}{|l|}{ Thrombus formation } & \\
\hline Localization & \multirow{2}{*}{\multicolumn{2}{|c|}{$\begin{array}{l}\text { iT } \\
21 d\end{array}$}} & Not detected \\
\hline Interval to surgery & & & $10 \mathrm{mo}>$ \\
\hline
\end{tabular}


TABLE 2. Continued

\begin{tabular}{lll}
\hline & \multicolumn{1}{c}{ Patient $\mathbf{9}$} & \multicolumn{1}{c}{ Patient $\mathbf{1 0}$} \\
\hline Symptoms & \multicolumn{1}{c}{ Cerebrovascular accident } \\
Prophylaxis of thrombus at diagnosis & Heparin & Heparin SC (PLE) \\
Potential predisposing circumstances & Postop immobilization & PLE, fenestrated occclusion \\
Thrombus therapy & Warfarin for 3 mo & Warfarin \\
Long-term prophylaxis & ASA & Warfarin
\end{tabular}

ASA, Acetylsalicylic acid; CAVSD, common atrioventricular septal defect; DILV, double inlet left ventricle; DORV, double outlet right ventricle; CPC, cavopulmonary connection; HLHS, hypoplastic left-heart syndrome; iT, intra-atrial tunnel; MGA, malposition of the great arteries; $P A / I V S$, pulmonary atresia/intact ventricular septum; $P A P V D$, partial anomalous pulmonary venous drainage; $P L E$, protein-losing enteropathy; $P S$, pulmonary stenosis; $r t-P A$, recombinant tissue-type plasminogen activator; $S A$, single atrium; $S C$, subcutaneous; $S P S$, subpulmonary stenosis; $S V$, single ventricle; $S V C$, superior vena cava; SVT, supraventricular tachycardia; TA, tricuspid atresia; TAPVD, total anomalous pulmonary venous drainage; TCPA, total cavopulmonary anastomosis; TGA, transposition of the great arteries.

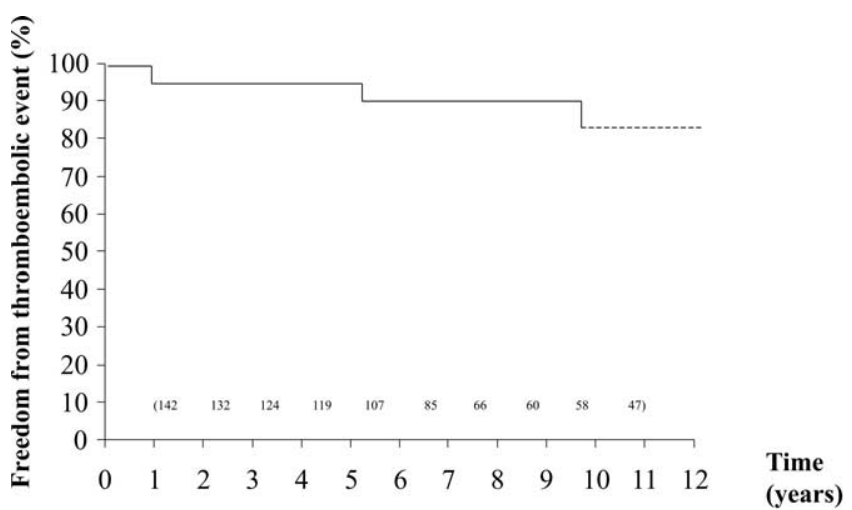

Figure 2. Kaplan-Meier estimate for freedom from thrombotic or thromboembolic events.

initiated because of a thromboembolic event in 7 patients or the development of potential predisposing causes for thromboembolic complications (Table 3); prophylactic anticoagulation was begun 16 to 110 months (mean $56.2 \pm 32.2$ months) postoperatively. None of these patients had bleeding complications. Patients without any antithrombotic prophylaxis had significantly longer mean follow-up (123.8 \pm 32.3 months) compared with patients who received warfarin (101.4 \pm 46.6 months; $P=.04)$ or ASA $(69.7 \pm 34.8$ months; $P=.005)$.

Atrial dysrhythmia defined as IART occurred in 18 patients (12.6\%); 6 of these patients who required antiarrhythmic medication received warfarin (Table 3). Evidence of protein-losing enteropathy was found in 9 patients $(6.3 \%)$. Four of these patients had a history of thromboembolic complications with or after the onset of symptoms of protein-losing enteropathy and were subsequently placed on warfarin. Two additional patients had symptomatic proteinlosing enteropathy and received prophylactic anticoagulation treatment 23 and 60 months postoperatively. Slow blood flow phenomenon and ventricular dysfunction documented on echocardiographic follow-up studies led to prophylactic warfarin medication in 7 adolescent patients (aged
TABLE 3. Special indications for anticoagulant treatment with warfarin (25/142 patients)

\begin{tabular}{ll}
\hline Prior thrombus formation/thromboembolic event & 7 \\
$\quad$ (including 4 patients with PLE) & 2 \\
Tunnel-fenestration & 1 \\
Residual PA trunk & 6 \\
Atrial dysrhythmia/IART & 3 \\
Slow blood flow phenomenon on TTE & 4 \\
Ventricular dysfunction & 3 \\
Polycythemia & 1 \\
Venous congestion/elevated PA pressure & 1 \\
After transcatheter intervention (fenestration & \\
$\quad$ closure) &
\end{tabular}

$I A R T$, Intra-atrial reentry tachycardia; $P A$, pulmonary artery; $P L E$, proteinlosing enteropathy; TTE, transthoracic echocardiography.

136-245 months) 40 to 110 months postoperatively. After transcatheter procedures (closure of residual interatrial communications/fenestrations in 11 patients and device closure of a reopened left superior caval vein draining into the coronary sinus in 3 patients), patients continued to receive ASA, except for 3 patients who remained on warfarin $(2$ patients with a history of thromboembolic complication or protein-losing enteropathy). None of these patients had a late thromboembolic event during follow-up.

\section{Discussion}

The number of reports on thrombotic and thromboembolic complications after the Fontan operation is increasing, reflecting longer postoperative survival and duration of follow-up. Recent studies reported an incidence as high as 20\% for systemic venous and arterial thrombosis with an unknown ratio of asymptomatic patients. ${ }^{4-6,18}$ Therefore, the true incidence of cardiac thrombi is unknown.

Anticoagulation strategies have been considered with various ideas concerning the indication and type and duration of therapy. $8,13,16$ Some of these suggestions, however, were based on the experience of patients undergoing previous types of univentricular palliation. These included a high 
proportion of patients with atriopulmonary anastomosis or total cavopulmonary anastomosis and a blind pouch left after main pulmonary artery ligation/division. Because of a high incidence of late thromboembolic complications in these patients, long-term anticoagulant therapy with warfarin was recommended for all patients undergoing a Fontan procedure irrespective of the surgical technique or additional predisposing factors. ${ }^{9,13}$ On the basis of the assumption that potential risk factors may exist and can be used as a rationale to decide on different anticoagulation treatment regimens, we assessed the relationship between individualized treatment and outcome, that is, thromboembolic problems in patients after total cavopulmonary anastomosis. Our results show that the surgical technique is relevant in 2 aspects. None of the 16 patients with an autologous tunnel procedure had thrombus formation, although they did not receive any anticoagulation medication as part of our strategy. This may be related to the nonturbulent systemic venous flow dynamics with the preservation of a somewhat pulsatile flow by atrial contraction and less respiratorydependent venous return. ${ }^{19}$ Thrombus formation in the residual pulmonary trunk after pulmonary artery ligation or division with the risk of arterial embolization and cerebral infarction is not a rare event; it has been described in approximately $30 \%$ to $50 \%$ of patients with thrombus formation after univentricular palliation. ${ }^{9,18}$ However, it was our policy to start to close any pulmonary trunk at the pulmonary valve annulus level. We succeeded in all but 1 patient, who was then administered anticoagulation treatment. Because of the potentially serious sequelae, diagnosis of a thrombus in the pulmonary stump should prompt urgent removal and closure of the pulmonary valve even in asymptomatic patients. ${ }^{16}$

As reported in the literature, the type of material used for creation of the lateral tunnel or the presence of fenestrations did not affect the risk of stroke. ${ }^{7,17,18}$ After tunnel fenestration, a high proportion of spontaneous fenestration closures during follow-up has been described, limiting the potential risk of paradoxic thromboembolism. ${ }^{20}$ In our study, patients with persistent tunnel fenestration were placed on ASA (except for 2 patients), although an increased risk of stroke has not been proven in these patients. ${ }^{7}$

Early experience in patients who underwent an extracardiac conduit procedure revealed a high incidence of thrombus formation, ${ }^{5,21}$ but the number of patients under extended follow-up is still limited. None of the young patients who had recently undergone an extracardiac conduit procedure at our institution were placed on warfarin. However, we never used prosthetic tubes in the extracardiac Fontan procedure; we used as much autologous tissue (mainly in situ pericardium) as possible.

All patients with a history of thrombus formation in our study had at least 1 potential predisposing factor that might increase the risk of thromboembolic complications. The findings of other investigators, ${ }^{4,7,22}$ (ie, supraventricular tachycardia and IART may promote thrombus formation on an atrial level) prompted us to anticoagulate our patients with recurrent atrial tachydysrhythmia. Thrombus formation in association with the diagnosis of protein-losing enteropathy occurred in 4 of our 10 patients. This clinical observation had not been made in the literature. The potential risk of imbalance of the procoagulant and anticoagulant factors in patients with protein-losing enteropathy, resulting from similar molecular weights for albumin, protein $\mathrm{C}$ and $\mathrm{S}$, antithrombin III, and factors II and X, had already been described by Cromme-Dijkhuis and associates. ${ }^{10}$ Patients with protein-losing enteropathy and thrombus formation in our study did not show a uniform pattern of coagulation factor abnormalities. Under therapy with warfarin, none of these patients experienced further thrombosis during follow-up.

The follow-up in our patients was too short and the number of patients was too small to confirm the impression of other studies that the incidence of arrhythmias and thromboembolic events increases with the duration of follow-up, especially after 10 years. $^{2,13}$ On the other hand, patients with long-term follow-up and adult patients are at risk for systemic ventricular dysfunction; in this case, we believe that anticoagulation treatment is indicated especially when contrast echocardiograms demonstrate a slow blood flow situation, which is probably caused by spontaneous microcavitations within the cavopulmonary connection. ${ }^{23}$ One major potential predisposing factor in our study was prolonged postoperative immobilization documented in 4 patients with thrombus formation. Postoperative heparinization was routinely started in all patients shortly after the Fontan procedure or noncardiac surgery (with prolongation of partial thromboplastin time to 50-60 seconds), as recommended in adults and adapted for children. ${ }^{6}$ However, disease states might coexist that influence plasma concentrations of antithrombin or the anticoagulant capacity of heparin by an increase in acute phase proteins. ${ }^{6,8}$ Coagulation factor abnormalities potentially predisposing to thromboembolic events have been described in recent reports in various constellations after the Fontan procedure, suggesting an unpredictable risk of imbalance in procoagulant and anticoagulant factors with the need for anticoagulation treatment. ${ }^{24,25}$ However, there is presently no coagulation profile that can be used to identify patients at increased risk for thrombus formation or permanent abnormal consumption of coagulation factors.

\section{Limitations of the Study}

Transesophageal echocardiography has proven to be the method of choice to identify intracardiac thrombi in the majority of asymptomatic patients, especially older children 
and young adults. ${ }^{5,9,23}$ Because transesophageal echocardiography was not performed on a routine basis in all of our patients, the true incidence of asymptomatic cardiac thrombi may have been underestimated.

The relatively small number of patients with a thromboembolic event during follow-up limits the possibility of identifying a risk factor with statistical significance.

\section{Conclusion}

In all of our patients, thrombus formation was associated with at least 1 additional potential predisposing factor, such as postoperative prolonged immobilization, protein-losing enteropathy, stenosis of the cavopulmonary anastomosis, or atrial arrhythmia, and seems to be highest in the first year after a total cavopulmonary anastomosis. Primary surgery with consequent closure of a patent pulmonary valve, thereby avoiding thrombogenic "blind" pulmonary artery stump, contributed to the low incidence of late thromboembolic events in our cohort. Because our prophylactic anticoagulation strategy proved effective in the prevention of thrombotic complications during long-term follow-up, we do not believe that initial anticoagulation therapy is routinely required in all young children after a total cavopulmonary anastomosis.

\section{References}

1. Stamm C, Friehs I, Mayer JE, et al. Long-term results of the lateral tunnel Fontan operation. J Thorac Cardiovasc Surg. 2001;121:28-41.

2. Freedom RM, Hamilton R, Yoo SJ, et al. The Fontan procedure: analysis of cohorts and late complications. Cardiol Young. 2002:10: 307-31.

3. Cromme-Dijkhuis AH, Hess J, Hahlen K, et al. Specific sequelae after Fontan operation at mid- and long-term follow-up. Arrhythmia, liver dysfunction and coagulation disorders. J Thorac Cardiovasc Surg. 1993;106:1126-32.

4. Rosenthal DN, Friedman AH, Kleinman CS, Kopf GS, Rosenfeld LE, Hellenbrand WE. Thromboembolic complications after Fontan operation. Circulation. 1995;92(9 Suppl):II287-93.

5. Shirai LK, Rosenthal DN, Reitz BA, Robbins RC, Dubin AM. Arrhythmias and thromboembolic complications after the extracardiac Fontan operation. J Thorac Cardiovasc Surg. 1998;115:499-505.

6. Monagle P, Karl TR. Thromboembolic problems after the Fontan operation. Semin Thorac Cardiovasc Surg Pediatr Card Surg Annu. 2002;5:36-47.

7. DuPlessis A, Chang A, Wessel D, et al. Cerebrovascular accidents following the Fontan operation. Pediatr Neurol. 1995;12:499-505.

8. Monagle P, Cochrane A, McCrindle B, Benson L, Williams W, Andrew M. Thromboembolic complications after Fontan procedures: the role of prophylactic anticoagulation. J Thorac Cardiovasc Surg. 1998;115:493-8.

9. Balling G, Vogt M, Kaemmerer H, Eicken A, Meisner H, Hess J. Intracardiac thrombus formation after the Fontan operation. J Thorac Cardiovasc Surg. 2000;119:745-52.

10. Cromme-Dijkhuis AH, Henkes CM, Bijleveld CM, Hillege HL, Bom VJ, van der Meer J. Coagulation factor abnormalities as possible thrombotic risk factors after Fontan operations. Lancet. 1990;336: 1087-90.

11. Rauch R, Ries M, Hofbeck M, Buheitel G, Singer H, Klinge J. Hemostatic changes following the modified Fontan operation (total cavopulmonary connection). Thromb Haemost. 2000;83:678-82.

12. Kaulitz R, Luhmer I, Bergmann F, Rodeck B, Hausdorf G. Sequelae after the modified Fontan operation: postoperative haemodynamic data and organ function. Heart. 1997;78:154-9.

13. Seipelt RG, Franke A, Vazquez-Jimenez V, et al. Thromboembolic complications after Fontan procedures: comparison of different therapeutic approaches. Ann Thorac Surg. 2002;74:556-62.

14. Kugler JD. Sinus node dysfunction. In: Gillette PC, Garson AJR, editors. Pediatric arrhythmias: electrophysiology and pacing. Philadelphia: WB Saunders; 1990. p 250-300.

15. Mertens L, Hagl DJ, Sauer U, Somerville J, Gewillig M. Protein-losing enteropathy after the Fontan operation: an international multicenter study. J Thorac Cardiovasc Surg. 1998;115:1063-73.

16. Madan N, Robinson BW, Jacobs ML. Thrombosis in the proximal pulmonary artery stump in a Fontan patient. Heart. 2002;88:396.

17. Coon PD, Rychik J, Novello RT, Ro PS, Gaynor JW, Spray TL. Thrombus formation after the Fontan operation. Ann Thorac Surg. 2001;71:1990-4.

18. Jacobs ML, Pourmoghadam KK, Geary EM, et al. Fontan's operation: is aspirin enough? Is Coumadin too much? Ann Thorac Surg. 2002; 73:64-8.

19. Hashimoto K, Kurosawa H, Tanaka K, et al. Total cavopulmonary connection without the use of prosthetic material: technical considerations and hemodynamic consequences. J Thorac Cardiovasc Surg. 1995;110:625-32.

20. Jacobs ML, Rychik J, Zales VR, Geary EM. Modification of the fenestrated Fontan operation: spontaneous closure of multiple small fenestrations. In: Imai Y, Momma K, editors. Proceedings of the Second World Congress of Pediatric Cardiology and Cardiac Surgery. New York: Futura; 1998. p 357-9.

21. Vouhe PR. Fontan completion: intracardiac tunnel or extracardiac conduit? Thorac Cardiovasc Surg. 2001;49:27-9.

22. Ghai A, Harris L, Harrison DA, Webb GD, Siu SC. Outcomes of late atrial tachyarrhythmias in adults after the Fontan operation. J Am Coll Cardiol. 2001;37:585-92.

23. Stümper O, Sutherland GR, Geuskens R, Roelandt J, Bos E, Hess J. Transesophageal echocardiography in evaluation and management after a Fontan procedure. J Am Coll Cardiol. 1991;17:1152-60.

24. Odegaard C, McGowan FX, Zurakowski D, et al. Procoagulant and anticoagulant factor abnormalities following the Fontan procedure: increased factor VIII may predispose to thrombosis. J Thorac Cardiovasc Surg. 2003;125:1260-7.

25. Tomita H, Yamada O, Ohuchi H, et al. Coagulation profile, hepatic function and hemodynamic followings after Fontan-type operations. Cardiol Young. 2001;11:62-6. 